\title{
Influências do Ensino Médio nas perspectivas de futuro de seus estudantes
}

High School influences in the future prospects of their students

\author{
Wender Faleiro* \\ Universidade Federal de Goiás \\ Roberto Valdes Puentes** \\ Universidade Federal de Uberlândia \\ Milena Cristina Aragão*** \\ Faculdade Estácio
}

Resumo O presente estudo objetivou conhecer a percepção que os estudantes do Ensino Médio de Uberlândia, MG possuem sobre a influência da escola em suas vidas. O estudo foi realizado em sete escolas, com 1.040 alunos de todos os três níveis de seriação do Ensino Médio. Para a maioria dos alunos entrevistados a escola representa algum tipo de $m u-$ dança positiva e, para muitos, a única finalidade da escola é melhorar as possibilidades de empregabilidade. Por outro lado, muitos demonstram estarem mais conscientes da importância das relações interpessoais, da valorização das diferenças e da diversidade cultural, e querem ter mais voz e espaços no processo educativo. Os jovens estão ansiosos por uma escola que lhes proporcione chances mínimas de trabalho e que se relacione com suas experiências presentes.

PalaVRas-CHAVE: Ensino médio; Escola; Projetos de vida; Juventudes.

Abstract This study examines perceptions that the high school students of Uberlândia, MG have about the school's influence in their lives. The study was conducted in seven schools with 1,040 students from all three levels of ranking of high school. For most students interviewed school is some kind of positive change and, for many, the only purpose of school is to improve the employability of possibilities. On the other hand, show many are aware of the importance of interpersonal relations, appreciation of differences and cultural diversity, and want to have more say and spaces in the educational process. Young people are eager for a school that provides them with minimal chances of work and that relates to your present experiences.

KEYWORDS: High school; School; Life projects; Youths. 


\section{Introdução}

Estudar juventudes e Ensino Médio é um desafio haja vista envolver várias conjunturas, concepções, preconceitos, sonhos e perspectivas de futuro, além é claro da atuação do poder público na consolidação de políticas públicas. Segundo o Conselho Nacional de Juventude ${ }^{1}$, são considerados jovens aqueles (as) cidadãos (as) que se encontram entre os 15 e os 29 anos. E, a Política Nacional da Juventude reitera essa faixa etária para a juventude brasileira, período compreendido entre a puberdade e a idade adulta (CONJUVE, 2006). Dentro deste conjunto temporal, Kummer \& Colognese (2013), subdivide juventude em três segmentos etários: jovens-adolescentes, de 15 a 17 anos; jovens-jovens, de 18 a 24 anos; e jovens adultos, de 25 a 29 anos.

Contudo, é preciso ir além da faixa etária, dessa forma Castro (2009) reitera que as juventudes devem ir além do recorte de população específica, evidenciar as interações sociais e as configurações em que são vivenciadas, mas afima que esse grupo está mais marcado por relações de hierarquia social. A juventude deve ser entendida considerando suas especificidades e transformações, Abramo; Freitas \& Sposito (2002) chama-nos a atenção que ao se trabalhar com a juventude deve-se considerar a diversidade social, econômica e cultural em que está inserida.

Conforme dados do INEP (2014), mais de 50\% dos jovens de 15 a 17 anos ainda não atingiram o Ensino Médio e milhões de jovens com mais de 18 anos e adultos não o concluíram. De acordo com o documento Sintese dos Indicadores Sociais do IBGE: uma análise das condiçôes de vida da população brasileira (IBGE, 2014), constatase que a taxa de frequência bruta às escolas dos jovens de 15 a 17 anos é de $85,2 \%$, já a taxa de escolarização líquida desses jovens é de 50,9\%. Em regiões mais pobres do país, como o Nordeste, por exemplo, a taxa de escolaridade líquida é de apenas 39,1\%. Enquanto que a taxa de aprovação no Ensino Médio brasileiro é de 75,2\%, de reprovação e de abandono são, respectivamente, de 14,1\% e de 13,2\% (INEP, 2014). Vale ressaltar que dos poucos jovens que terminam o Ensino Médio no Brasil têm acesso à universidade, segundo Souza \& Menezes (2014) é da ordem de 3\%.

Mediante esse relato, mesmo que apresentem limites, sugere-se que voltemos o olhar aos estudantes desse nível de ensino. Daí surge a seguinte pergunta: quais mudanças e influencias a escola marcou e marca nos planos e perspectivas de futuro de seus jovens estudantes? Neste contexto, o presente estudo objetivou conhecer a percepção que os estudantes do Ensino Médio de Uberlândia, MG possuem sobre a influência da escola em suas vidas. A opção por focar este estudo, nessa temática, se fundamenta na relevância e abrangência do mesmo, já que se trata de um tema pouco desenvolvido e seus resultados levarão à reflexão e, certamente, produzirão impactos positivos na melhoria da qualidade do Ensino Médio público.

\section{Metodologia}

A presente pesquisa tem abordagem qualitativa, e utilizou-se de questionários para a coleta dos dados, o que permitiu trabalhar com uma grande amostra. $\mathrm{O}$ estudo foi realizado no município de Uberlândia, sede da Superintendência de Ensino 
Regional de Uberlândia (SRE), que dispõe de 234 estabelecimentos educacionais, 48 deles de Ensino Médio, dos quais 26 são de caráter estadual. Dos 26 estabelecimentos estaduais de ensino do município de Uberlândia-MG, que oferecem Ensino Médio, foram escolhidas sete escolas, seguindo o critério das médias gerais obtidas por cada estabelecimento de ensino no Exame Nacional do Ensino Médio (ENEM), sendo três com notas superiores a média do município; e quatro com notas inferiores à média. $\mathrm{O}$ anonimato foi mantido às Escolas.

A população/sujeitos do estudo foi composta pelos alunos das sete escolas estaduais, matriculados no Ensino Médio diurno. A amostra foi integrada pela totalidade de alunos presentes no dia da aplicação dos questionários e que aceitaram - de maneira esclarecida e livre - participar da pesquisa.

O questionário era composto de 20 questões objetivas (com aproximadamente 100 itens) com a finalidade de traçar o perfil dos alunos, suas representações sobre a escola, sobre os docentes, sobre o ambiente familiar, e sobre sua disposição pessoal para o estudo e o resultado de seu empenho escolar. Em particular, nesse estudo, utilizou-se duas perguntas abertas, a primeira: Que tipo de mudanças a escola trouxe para você como estudante, com sua família, com os colegas, com a sociedade ou como pessoa em geral? E, a segunda: Espaço aberto para expressar outras questões de seu interesse que não tenham sido tratadas no questionário.

A análise dos dados consistiu na organização sistemática dos dados coletados em planilha utilizando o programa Microsoft Excel 2007, por categorias e indicadores, com o objetivo de aumentar a compreensão sobre os fenômenos em estudo e facilitar a sua manipulação, sintaxe, procura de padrões, descoberta de aspectos importantes.

\section{Resultados e discussões}

No total, 1.040 alunos responderam os questionários de todos os três níveis de seriação do Ensino Médio, tendo uma distribuição equitativa com $36 \%$ que cursavam o $1^{\circ}$ ano; $32 \%$ o $2^{\circ}$ ano e $32 \%$ o $3^{\circ}$ ano. Desses, a maioria foi do sexo feminino $(58,9 \%)$, a maioria é jovem-adolescente de 15 a 17 anos (83,3\%), e os demais (26,7\%) possuem de 18 a 24 anos de idade.

Da totalidade de alunos que responderam aos questionários 84 (8,1\%) disse que a Escola não trouxe nenhuma mudança em suas vidas, estatisticamente o número seria baixo, mas estamos nos referindo a 84 vidas, que por algum motivo estão desmotivadas, desconectadas com a escola e com perspectivas positivas referentes ao seu futuro. Isso é preocupante, pois nesses 84 jovens, a escola não conseguiu mostrar e nem cumprir o seu papel de preparar esses jovens para inserções sociais, políticas, culturais, laborais e, ao mesmo tempo, capazes de intervir e problematizar as formas de produção e de vida.

Os estudos de Abramovay e Castro (2003) de abrangência nacional e explora várias dimensões do cotidiano do Ensino Médio, não encontraram relações nítidas de "mudança" qualitativa que lhe permitiram relacionar com os anseios dos jovens, 
mas a falta de "mudança" na vida desses jovens traz consigo sintomas de fracasso, mal -estar, conflito, violência, dificuldade de integração por parte dos jovens e, sobretudo, ausência de sentido da experiência escolar.

Aos demais $(91,9 \%)$ a escola representou algum tipo de "mudança", vale ressaltar que todas foram positivas. As mais expressivas foram separadas e nomeadas em dez categorias:

$1^{\text {a }}$ - As que relacionaram a escola como detentora do conhecimento e ela era a possibilidade de um futuro melhor:

Trouxe-me uma boa maneira e como devermos agir para estudar e ser alguém no futuro (Aluno, 17 anos, grupo II).

$2^{\text {a }}$ - Da escola como um local de convivência com a diversidade humana, de relações interpessoais e sociais:

A escola me ajuda a relacionar com a sociedade, podendo entender, e aceitar as opiniões de todos, e me deu facilidade de expressar em público (Aluna, 16 anos, grupo I).

$3^{a}$ - Como transformadora da realidade e preparação para a vida em sociedade:

Ofereceu-me um conhecimento sobre ares que dificilmente teria acesso fora dela, assim tenho mais domínio, para discutir estes assuntos, e viver melhor em sociedade (Aluno, 17 anos, grupo I).

$4^{\mathrm{a}}$ - Como preparadora para a vida profissional:

Está me ajudando a ser um bom profissional, uma boa pessoa no futuro (Aluno, 17 anos, grupo I).

$5^{\mathrm{a}}$ - Como formadora de autonomia na busca do conhecimento:

A escola ampliou meus conhecimentos científicos me adequando a comportamentos mais cultos. Já ensinei várias coisas para minha mãe, minha prima, etc. e com meus colegas eu melhor o as formas de me comunicar e expressar meus pensamentos (Aluno, 16 anos, grupo I).

$6^{\mathrm{a}}$ - Como potencializadora do amadurecimento pessoal e formação para a cidadania

A escola me fez enxergar lados que antes nunca havia imaginado, como cultura, a partir do momento que entrei no Ensino Médio eu amadureci minha personalidade cresceu hoje me sinto mais forte pra expor minha opinião e tenho mais conhecimento para argumentar hoje sei que cresci como gente, acho que agora eu só penso no meu futuro e isso realmente faz diferença (Aluna, 17 anos, grupo II). 
$7^{\mathrm{a}}$ - Como criadora de um pensamento crítico:

As mudanças que a escola trouxe em minha vida são muitas dentre elas: crescimento pessoal, maturidade, capacidade de avaliar situações-problemas, respeitar as diferenças, entre outros. Além disso, a escola me conscientizou principalmente da qualidade e da realidade do ensino público brasileiro. Portanto, a vida escolar ajudou diretamente em todas as minhas relações pessoais e com certeza no que refere à vida social (Aluno, 17 anos, grupo II).

$8^{\mathrm{a}}$ - como desenvolvedora da comunicação, da linguagem e curiosidade:

Pois é graças aos estudos que desenvolvi uma capacidade de argumentar e expor minhas ideias através da escrita ou fala (Aluna, 16 anos, grupo I).

$9^{a}$ - como esclarecedora dos direitos e deveres

A escola tem grande influência na vida das pessoas e traz muitas mudanças como a capacidade de compreensão, o aprendizado de direitos e deveres da sociedade e a capacidade de aprender matérias importantes e assim estar pronta para entrar em uma faculdade, ter meu trabalho e dar continuidade a vida. Assim, concluímos que a escola influência na personalidade, no respeito, na educação e em vários outros na minha vida (Aluno, 17 anos, grupo I).

$10^{\mathrm{a}}$ - como transformadora e motivadora ao prosseguimento dos estudos

Considero a escola uma parte muito importante em minha vida, pois me fez crescer como pessoa, me fez adquirir conhecimento, conhecer novas pessoas, aprender a defender pontos de vista opiniões, etc. Enfim a escola é muito importante para minha vida (Aluno, 15 anos, grupo I).

Pelas falas, percebe-se que a presença de concepções do senso-comum a respeito dos fins da educação está bem marcante em nossa sociedade e, para muitos, essa é a única finalidade da escola, ou seja, melhorar as possibilidades de empregabilidade e esse vir a ser mais bem remunerado e menos penoso.

Observa-se, ainda, nas respostas dos alunos e, também, no cotidiano escolar, que a escola é a garantia de ser alguém no futuro, esse pensamento demonstra claramente a distorção dos sentidos da formação humana da escola, e a forte presença do ideário capitalista. Os quais não deixam os alunos viverem e perceberem o presente, saberem sua importância individual e coletiva, das várias facetas e papéis sociais. Prendendo-os apenas na preparação para o trabalho, a fim de atender as crescentes demandas da força motriz do capitalismo e, vislumbrarem com um futuro distante e promissor onde poderão, se esforçarem, estudarem e trabalharem muito, terem uma melhor remuneração e poderem desfrutar de todos os benefícios que a sociedade capitalista oferece.

Esse discurso está entremeado em nossa sociedade e até mesmo na própria legislação educacional - a exemplo da Lei de Diretrizes e Bases da Educação Nacional (9394/96) e das Diretrizes Curriculares Nacionais para o Ensino Médio (DCNEM) nas quais se percebe a demasiada importância que oferecem, principalmente no ensino Médio, para a preparação para o trabalho em detrimento da formação humana. 
Ressalta-se que não se desconhece a função do trabalho, mas se-defende seu principio educativo e sua integralidade com a ciência e a cultura. Apenas teme-se que as classes menos favorecidas não tenham o acesso devido ao conhecimento produzido social e historicamente, e continuem presos à ideologia profissionalizante da escola.

O Estado justifica a formação para o trabalho tornar o Ensino Médio mais atrativo aos jovens, haja vista ser uma alternativa de formação e de profissão àqueles que não irão ingressar no ensino superior, corroborando na persistência e sobrevivência da dualidade histórica do ensino médio, pois às elites não importam esse tipo de formação, pois a terão no ensino superior.

Por outro lado, se percebe com positividade as demais falas, e que os alunos realmente estão mais críticos e observadores da realidade à sua volta. Que já estão mais conscientes da importância das relações interpessoais da valorização das diferenças e da diversidade cultural. Destacando, que a escola o preparou para a autonomia e para o prosseguimento dos estudos.

Nessa perspectiva surge a necessidade de refletirmos um pouco sobre o público desse nível de ensino da Educação Básica, pois entender o estudante do Ensino Médio é no mínimo necessário para percebê-lo como pessoa, que como qualquer outro ser humano possui valores, comportamentos, visões de mundo, interesses e necessidades singulares. São seres ansiosos e temerosos das incertezas do futuro e estão em busca de espaço e reconhecimento da sociedade.

É necessário não ter preconceitos depreciativos reduzidos a um recorte etário, como tempo de liberdade, de experimentação e irresponsabilidade. É um importante passo a ser tomado, principalmente, pelos gestores e professores que passam um longo período com eles, e muitas vezes podem ser os únicos a ter oportunidade de orientá-los e entendê-los. Dentro deste perfil, encontramos como aluno do Ensino Médio o sujeito inserido numa etapa de desenvolvimento humano conhecido como “jovem-adolescente", vista por alguns teóricos da Psicologia (ABERASTURY, 1980; OZELLA, 1999) como um processo contraditório, que não tem um sentido único, não é homogêneo, muito menos linear e, tampouco provido de um único significado.

Diante deste contexto, uma das definições correntes insere-se na perspectiva biomédica, que naturaliza e universaliza o processo da adolescência, para os biomédicos, a adolescência é considerada uma etapa de transição entre a infância e a idade adulta, tendo como base as transformações púberes, de caráter biológico, que, por sua vez, desencadeariam mudanças psicológicas e sociais, até atingir a maturidade (PERES \& ROSENBURG, 1998). Já o processo de adolescência, numa perspectiva psicológica, tem, historicamente, sua concepção balizada pela crença de que esta é uma etapa da vida marcada por tormentos, conflitos vinculadas à emergência da sexualidade. Também é entendida como uma fase de dificuldades em estabelecer uma identidade própria, sendo vista como "modo de vida" entre a infância e a idade adulta, dentro da qual o adolescente possui uma mentalidade própria com um psiquismo característico dessa fase (DEBESSE, 1946; ERIKSON, 1976; ABERASTURY, 1980). 
A partir de tais representações, emergiu uma concepção naturalista e universal sobre o adolescente, que é questionada por outros psicólogos que se debruçam nesta temática. Santos (1996), por exemplo, coloca em dúvida essa tradição que considera a adolescência como uma fase crítica, que pressupõe uma crise preexistente (marcada pela rebeldia, instabilidade afetiva, tendência grupal, crises religiosas, contradições e crises de identidade) e que enfatizam as estruturas internas como propulsionadoras do desenvolvimento. Para o autor, este é um movimento que tende a desconsiderar o contexto social e cultural, decorrendo na idéia de que existe um único tipo de jovem, oriundo de um tipo de contexto. Ademais, Santos (1996) sinaliza para o olhar adultocêntrico sobre o jovem, isto é, a partir da perspectiva do adulto.

Conforme Bock (1997) é importante suplantar a visão naturalizante e patologizante da adolescência presente na Psicologia, sugerindo como caminho refletir sobre a adolescência como uma construção histórica, cultural e socialmente criada pelo homem. Esta é constituída como significado na cultura, na linguagem que permeia as relações sociais. Quando se define a adolescência como "isto ou aquilo", está se constituindo significações a partir de realidades sociais e de marcas que serão referências para a constituição dos sujeitos. A adolescência não é um período natural do desenvolvimento. É um momento significado e interpretado pelo homem.

Seguindo esta linha de pensamento, concebe-se, portanto, que o jovem não é uma essência, mas um constante vir a ser, apresentando características que surgem e/ou desenvolvem-se nas relações que ele estabelece com o outro, com o mundo social oportunizando a construção incessante e numa trajetória de mão dupla de seu mundo psíquico. Logo, ao conceituar Adolescência, enquanto fases do desenvolvimento humano, olhando apenas uma de suas facetas têm-se um conceito equivocado e reducionista, haja vista que o ser humano só existe no social, nasce e se desenvolve a partir das nas relações sociais, em um dado contexto sócio-histórico-cultural. Para Dayrell et al (2014) nenhum indivíduo nasce homem, mas constitui-se e se produz como tal, dentro do projeto de humanidade do seu grupo social, num processo contínuo de passagem da natureza para cultura, ou seja, cada pessoa, ao nascer, vai sendo construído e vai se construindo enquanto ser humano. Para ele, são as relações sociais que educam, isto é, formam, produzem pessoas em suas realidades singulares mais profundas.

Diante deste cenário é possível identificar que a escola comete equívocos ao homogeneizar os alunos do Ensino Médio, na medida em que partem do princípio de que estes procuram a escola com as mesmas expectativas e necessidades, desconsiderando as diferenças de gênero, idade, origem social e experiências vivenciadas. Assim, a instituição escolar e seus atores levam o lema que todos são iguais, logo atendem a todos da mesma forma, com a mesma organização do trabalho escolar, mesma grade e currículo. Essa homogeneização das pessoas é também transferida às instituições de ensino, culminando numa visão de escola como uma instituição única, com os mesmos sentidos e objetivos, tendo como função garantir a todos o acesso ao conjunto de conhecimentos socialmente acumulados pela sociedade.

A segunda questão: "Espaço aberto para expressar outras questôes de seu interesse que não tenham sido tratadas no questionário" foi respondia por 136 estudantes 
$(13,1 \%)$ sendo considerada uma boa participação dos alunos, haja vista ser uma pergunta aberta e optativa corroborando com as respostas da $1^{\text {a }}$ questão na qual os alunos disseram que a escola estimulou o pensamento crítico e o desenvolvimento da expressão de suas ideias. Um aluno até agradeceu pelo espaço aberto para que ele pudesse ser 'ouvido': "esta pesquisa é a base para que possamos nos expressar e abertamente, expor a nossa opinião" (aluno Grupo I, 16 anos). Duas alunas usaram o espaço para elogiar sua escola, "adoro minha escola; alguns professores e o ensino oferecido".

Mas, a maioria utilizou o espaço para reclamar da infraestrutura, gestão e professores, sendo que 32 alunos reclamaram de seus professores quanto à profissionalização, relacionamento, desinteresse, assiduidade e pontualidade:

Falta de educação de alguns professores, e direção, de não deixar nos alunos argumentar alguma questão, acham que são o dono da razão, e não oferecem espaço para nos escutar.

Em defesa dos professores um aluno se manifestou:

Os professores precisam trabalhar mais que um turno para ganhar um salário decente e isso acaba atrapalhando suas aulas (não rende 100\%), e ficam sem tempo para preparar melhor as aulas.

Ainda 29 solicitaram melhores condições de ensino, aulas extras e de reforço, novas metodologias e disciplinas extracurriculares:

E o que precisa também é a disposição para aulas de reforço em outros horários ou em outros dias escola ter lugares de pesquisa e estuda para todos os alunos e melhor atendimento destes em minha opinião o laboratório tinha que ser mais liberado pros alunos por que no meu caso eu nunca participei de uma aula no laboratório, e eu queria que num fosse só aula normal podia ter coisas diferentes para estimular os alunos a vim pra escola e não ficar em casa sem fazer nada, podia ter mais passeios durante o ano, por que cansa só fica na sala estudando, é muito coisa de rotina e eu sei que a escola é capaz de mudar isso, vocês vão ver se mudar um pouco a rotina o tanto que vai mudar a frequência dos alunos na escola vão todos querem vim pra escola, o estudo é importante mais só estuda na sala fica chato podia ter aula preparada no computador, prova trabalhos podia mudar um pouco podia deixa agente fazer as provas no computador ia ser muito legal, por que o que adianta ter o computador se poder usar ele, eu nunca tive uma aula aqui , eu já vi muitos anos aqui mais eu mesma nunca vim.

Mais 25 alunos reclamaram da infraestrutura, limpeza do espaço escolar e a disponibilidade de laboratórios de informática e material multimídia:

Creio que as escolas públicas precisam ser reformadas de maneira ampla e geral. Os laboratórios e sala de vídeo, por exemplo, não comportam e não estão preparados para receber e proporcionar aos estudantes, um bom aprendizado prático. $\mathrm{E}$ os banheiros também, que além de poucos são precários. 
$\mathrm{Na}$ sequência, 14 disseram sobre o excesso de regras na escola e falta de motivação e incentivo nos estudos:

Reconhecimentos de alunos que querem, estão colocando a culpa em todos, começa a reconhecer e dar oportunidade para os que têm dificuldade, mas que querem realmente algo na vida, pessoas que estão dispostas a ter um ensino superior com planos de vida, é isso que precisa reconhecimentos e prioridade para os que querem! Estamos criando monstros, ta na hora de mudar isso, vamos dar prioridade para os que querem e principalmente, dar valor!

Sete reclamaram da gestão e dos funcionários da escola:

Mudança das autoridades da escola, pois eles acham que são pessoas mais inteligentes do que os outros e têm o poder de gritar com os alunos, e não dão assistência ideal para melhor aprendizagem. tais autoridades citadas que são muito brutas e agem com falta de educação, como: supervisores, e alguns outros.

Cinco disseram que a escola não ouve os alunos:

Eu acho que tinha que escutar mais as opiniões dos alunos, em questão da escola. Porque na nossa escola os alunos não estão podendo ter opinião de nada.

Quatro reclamaram da relação familiar e falta de tempo na influencia em sua qualidade de ensino:

Não dá para estudar tanto fora da escola, pela falta de tempo por mais força de vontade que os alunos tenham em estudar. É muito complicado fazer tudo com plenamente "certo", pois às vezes não se tem tempo disponível para estudos, devido ao trabalho.

Quatro são contra a retirada de algumas disciplinas da grade curricular:

Achei uma lastima a disciplina de história ser destituída da carga horária do $3^{\circ}$ ano, pois para fazer um vestibular é de suma importância ter domínio, ao menos parcial, deste conteúdo. Outro problema é que o conteúdo programático nunca é concluído desde a 5 serie, sempre faltou terminar algo em alguma matéria. Quando chegamos de manhã os bebedouros e os banheiros estão sujos, devido ao uso da noite, uso é muito ruim.

Três alunos reclamaram da Greve e da reposição das aulas:

A reposição de aulas não foi feita devidamente, ocasionando uma perda para os alunos da rede pública.

Um reclamou da falta de acessibilidade na escola para pessoas com deficiência física e /ou mobilidade reduzida; dois sobre a indisciplina dos alunos; um da falta de espaço reservado para o aluno ajudar na preservação do ambiente escolar; um sobre a falta de segurança; dois sobre a falta de atividades recreativas e desportivas; dois sobre o transporte escolar; e um indagou sobre qual a melhor maneira e horário para estudar. 
Percebe-se que os alunos estão conscientes de seus direitos e deveres, que os mesmos querem ter voz e vez no processo educativo e querem melhores condições de ensino e aprendizagem, logo veem necessidades de maior motivação deles próprios e de seus docentes, necessidades de maior valorização e formação docente, de melhor distribuição da carga horária, disponibilidade de aulas extras para melhor consolidação dos conteúdos, de melhor ambiente e infraestrutura, e participação da família em seu processo de ensino.

Reafirmando um descompasso de muitos jovens, principalmente de famílias carentes, com a realidade que vivenciam na escola. Ao mesmo tempo em que reconhecem seu papel fundamental no que se refere à empregabilidade, não conseguem atribuir-lhe um sentido imediato (SPOSITO, 2005). Vivem ansiosos por uma escola que lhes proporcione chances mínimas de trabalho e que se relacione com suas experiências presentes. Para esses, o trabalho não se situa no futuro, já fazendo parte de suas preocupações presentes. Um estudo realizado com jovens de várias regiões brasileiras constatou que $60 \%$ dos entrevistados frequentavam escolas e desses $75 \%$ já estavam inseridos e/ou buscando inserção no mundo do trabalho (SPOSITO, 2005). Ou seja, o mundo do trabalho parece estar mais presente na vida desses sujeitos do que a escola. Por conseguinte, muitos jovens deixam a escola por causa do trabalho, seja por falta de tempo ou por agora não mais precisar dela, que já não era tão atrativa e significativa a ele.

O descompasso entre a escola e os jovens não deve ser visto, segundo o parecer CNE/CEB No 5/2011 como decorrente, nem de uma suposta incompetência da instituição, nem de um suposto desinteresse dos estudantes, mas deve-se considerar as transformações sociais em curso. Essas transformações estão produzindo sujeitos com valores, modos de vida e práticas sociais que os tornam muito diferentes das gerações anteriores (DAYRELL, et al 2014). Entender tal processo de transformação é relevante para a compreensão das dificuldades hoje constatadas nas relações entre os jovens e a escola.

Zibas (2009), ao analisar as relações entre juventude e oferta educacional observa que a ampliação do acesso ao Ensino Médio nos últimos 15 anos não veio acompanhada de políticas capazes de dar sustentação com qualidade a essa ampliação. É diante de um público extremamente diverso, que traz para dentro da escola as contradições de uma sociedade que avança na inclusão educacional, sem transformar a estrutura social desigual, mantendo acesso precário à saúde, ao transporte, à cultura e lazer, e ao trabalho, que o novo Ensino Médio se forja. As desigualdades sociais passam a pressionar a instituição escolar e a produzir novos conflitos.

\section{Considerações finais}

Para a minoria dos alunos entrevistados $(8,1 \%)$ a Escola não trouxe nenhuma mudança em suas vidas. Aos demais $(91,9 \%)$ a escola representa algum tipo de mudança positiva, porém com uma forte presença de concepções do senso-comum e, para muitos, a única finalidade da escola, é melhorar as possibilidades de empregabilidade e esse vir a ser mais bem remunerado e menos penoso. Também, que a escola é a 
garantia de ser alguém no futuro, essa triste realidade demonstra claramente a distorção dos sentidos da formação humana da escola, e a forte presença do ideário capitalista.

Por outro lado em muitas falas demonstram que os alunos estão mais críticos e observadores da realidade à sua volta. Que estão mais conscientes da importância das relações interpessoais da valorização das diferenças e da diversidade cultural. Relatam, que a escola o preparou para a autonomia e para o prosseguimento dos estudos.

Os alunos estão conscientes de seus direitos e deveres, que os mesmos querem ter voz e vez no processo educativo e querem melhores condições de ensino e aprendizagem, logo veem necessidades de maior motivação deles próprios e de seus docentes, necessidades de maior valorização e formação docente, de melhor distribuição da carga horária, disponibilidade de aulas extras para melhor consolidação dos conteúdos, de melhor ambiente e infraestrutura, e participação da família em seu processo de ensino.

Os jovens estão ansiosos por uma escola que lhes proporcione chances mínimas de trabalho e que se relacione com suas experiências presentes. Para esses, o trabalho não se situa no futuro, já fazendo parte de suas preocupações presentes. No Brasil, têm-se grandes dificuldades de cunho social que impedem o funcionamento eficaz das instituições escolares, pois as condições econômicas favorecem à maioria uma completa exclusão social torna a escola algo externo a vida dos alunos. Mas é exatamente em uma sociedade desigual e no estágio de desenvolvimento social como a nossa que a existência de uma escola para todos é necessária.

\section{Referências}

ABERASTURY, A. Adolescência. Porto Alegre. Artes Médicas.1980.

ABRAMO, H.W., FREITAS, M.V. E., SPOSITO, M. P. Juventude em debate. São Paulo: Cortez, 2002.

ABRAMOVAY, M.; CASTRO, M. G. Ensino Médio: múltiplas vozes. Brasília: UNESCO, MEC, 2003. 662p.

BOCK, A. M. B. As aventuras do Barão de Münchhausen na Psicologia: Um estudo sobre o significado do fenômeno psicológico na categoria dos psicólogos. Tese de Doutorado não publicada. Curso de Pós-Graduação em Psicologia Social. Pontifícia Universidade Católica de São Paulo. São Paulo - SP. 1997.

BRASIL. Lei de Diretrizes e Bases da Educação Nacional. Lei n. ${ }^{9}$ 9.394, de 20 de dezembro, Brasília, DF, 1996.

Parecer CNE/CEB No: 5/2011. Diretrizes Curriculares Nacionais para o Ensino Médio. Publicado no D.O.U. de 24/1/2012, Seção 1, Pág. 10.

CASTRO E. G. Juventude rural no Brasil: processos de exclusão e a construção de um ator político. Revista Latinoamericana de Ciencias Sociales, Niñez y Juventud. Universidad de Manizales y el Cinde, vol. 7, núm. 1, (enero-junio), 2009, pp. 179-208.

CONSELHO Nacional de Juventude. Política Nacional de Juventude: Diretrizes e Perspectivas. CONJUVE: São Paulo, 2006.

DAYRELL, J; CARRANO P.; C. L. MAIA, (Orgs.). Juventude e Ensino Médio: sujeitos e currículos em diálogo. Belo Horizonte: UFMG, 2014. 
DEBESSE, M. A adolescência. São Paulo. Europa-América. 1946.

ERIKSON, E. Identidade, juventude e crise. Rio de Janeiro. Zahar. 1976.

INSTITUTO Brasileiro de Geografia e Estatística. Síntese dos Indicadores Sociais do IBGE: uma análise das condições de vida da população brasileira. Rio de Janeiro, 2014. 214p.

INSTITUTO Nacional de Estudos e Pesquisas Educacionais Anísio Teixeira. Censo Escolar da Educação Básica 2013: resumo técnico / Instituto Nacional de Estudos e Pesquisas Educacionais Anísio Teixeira. - Brasília: O Instituto, 2014.39p.

KUMMER R.; COLOGNESE, S. A. Juventude rural no brasil: entre ficar e partir. Tempo da Ciência volume 20 número 39. p. 209-220.

OZELLA, S. Concepções de adolescente/adolescência: Os teóricos e os profissionais. Relatório apresentado para concurso de promoção na carreira docente não publicado. Pontifícia Universidade Católica de São Paulo. São Paulo, 1999.

PERES, F; ROSENBURG, C. P. Desvelando a concepção de adolescência/adolescente presente no discurso da saúde pública. Sociedade e Saúde, no 7 (1) p. 53-86, 1998.

SANTOS, B. R. A emergência da concepção moderna de infância e adolescência. Mapeamento, documentação e reflexão sobre as principais teorias. Dissertação de Mestrado não publicada. Curso de Pós-Graduação em Ciências Sociais (Antropologia). Pontifícia Universidade Católica de São Paulo. São Paulo - SP. 1996.

SOUZA, M. R. A.; MENEZES, M. Programa Universidade para Todos (PROUNI): quem ganha o quê, como e quando? Ensaio: Avaliação e Políticas Públicas em Educação. Rio de Janeiro , v. 22, n. 84, p. 609-633, Sept. 2014.

SPOSITO, M. P. Algumas reflexões e muitas indagações sobre as relações entre juventude escola no Brasil. In: ABRAMO, H.; BRANCO, P. P. M.(Org.). Retratos da juventude brasileira: análises de uma pesquisa nacional. São Paulo: Instituto Cidadania; Fundação Perseu Abramo, 2005. p. $87-128$.

ZIBAS, D. (Org.). O ensino médio e a reforma da educação, da escola e das políticas educativas. Belo Horizonte: Autêntica Editora, 2009.

\section{Nota}

${ }^{1}$ O Conselho Nacional de Juventude (CONJUVE), formado por representantes do poder público (20) e da sociedade civil (40), foi criado em agosto de 2005 para realizar estudos e propor diretrizes para as políticas públicas voltadas aos jovens. (Lei n o 11.129 de 30 de junho de 2005. Decreto no 5.490 de 14 de julho de 2005).

* Professor doutor da Universidade Federal de Goiás, Catalão, Goiás, Brasil.

** Professor doutor da Universidade Federal de Uberlãndia, Uberlândia, Minas Gerais, Brasil.

*** Professora doutora da Faculdade Estácio, Aracajú, Sergipe, Brasil. 


\section{Correspondência}

Wender Faleiro - Universidade Federal de Goiás/Regional Catalão - Campus I. Av. Dr. Lamartine Pinto de Avelar, 1120. Setor Universitário - CEP 75704-020, Catalão, Goiás - Brasil.

E-mail:wender.faleiro@gmail.com - robertopuentes@faced.ufu.br-mi.aragao@yahoo.com.br

Recebido em 05 de agosto de 2015

Aprovado em 23 de março de 2016 